\title{
Transport of Polar and Nonpolar Liquids in Softwood Imaged by Neutron Radiography
}

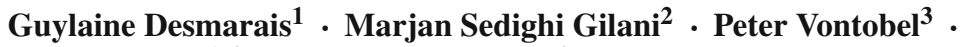 \\ Jan Carmeliet $^{1,4}$. Dominique Derome ${ }^{4}$
}

Received: 17 December 2015 / Accepted: 29 April 2016 / Published online: 11 May 2016

C) Springer Science+Business Media Dordrecht 2016

\begin{abstract}
The influence of the moisture capacity of cell walls on liquid transport in wood is studied using neutron imaging in combination with precision weighing. The time-dependent and spatial distribution of two liquids, one polar, water, and one nonpolar, decane, is documented during liquid uptake in the three orthotropic directions for samples of three softwood species: spruce and fir heartwood, and pine sapwood. Polar and nonpolar liquid uptake versus time is compared, the spatial distribution of the liquids within the samples is discussed, and the liquid volume and swelling profiles along the height of the samples are described in details. Water uptake is shown to be slower than decane uptake, due to water being adsorbed by the cells walls. Decane, due to its very low contact angle and high wettability compared to water, does not face much resistance from wood cellular features.
\end{abstract}

Keywords Capillary uptake $\cdot$ Nonpolar liquid $\cdot$ Softwood $\cdot$ Swelling $\cdot$ Neutron radiography

\section{Introduction}

The capillary uptake of liquid by a porous material depends both on the multiscale structure of the material and on the properties of the liquid. The structure of wood has two main scales: a cellular anisotropic architecture and a nanoporous cell wall material. At cellular scale, softwood consists mainly of longitudinal tracheid cells and radially oriented ray cells,

$凶$ Dominique Derome

dominique.derome@empa.ch

1 Chair of Building Physics, Swiss Federal Institute of Technology Zurich (ETHZ), Stefano-Franscini-Platz 5, 8093 Zürich Hönggerberg, Switzerland

2 Applied Wood Materials Laboratory, Swiss Federal Laboratories for Materials Science and Technology (EMPA), Überlandstrasse 129, 8600 Dübendorf, Switzerland

3 Paul Scherrer Institute, 5232 Villigen, Switzerland

4 Laboratory of Multiscale Studies in Building Physics, Swiss Federal Laboratory of Materials Research and Technology (EMPA), Überlandstrasse 129, 8600 Dübendorf, Switzerland 


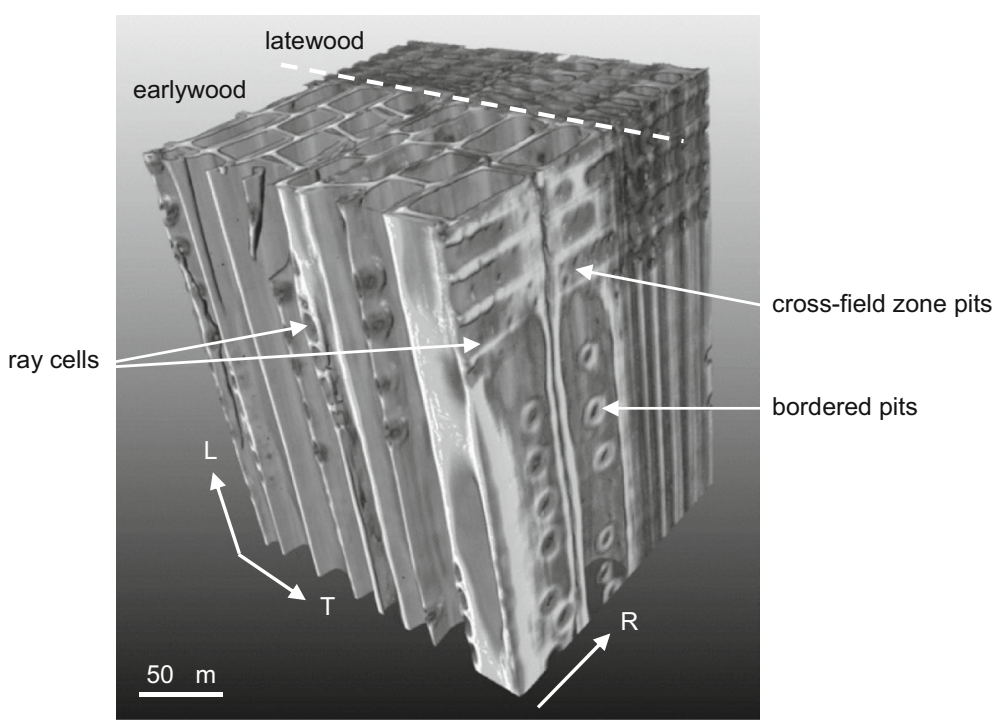

Fig. 1 Three-dimensional cellular structure of softwood (Norway spruce) acquired by synchrotron X-ray tomography, where $L$ refers to longitudinal, $T$ tangential and $R$ radial directions

the latter representing about $5 \%$ of wood volume. Over the course of a growing season in a temperate climate, the tracheids vary from earlywood cells to latewood cells, resulting in a growth ring pattern. Earlywood cells possess a larger diameter, a larger lumen and thinner walls than latewood cells do. Figure 1 shows the tridimensional cellular structure of softwood (spruce), imaged using high-resolution phase contrast synchrotron X-ray tomography. The lumens of the cells are connected by different types of openings: bordered pits between tracheids and differently shaped crossfield pits between tracheids and ray cells. In earlywood, bordered pits are situated mainly on the radial cell walls, while in latewood, for some species, bordered pits may be positioned equally on radial and tangential cell walls (Kitin et al. 2009; Koran 1977). When water withdraws from the lumens, through drying for example, a valvelike occlusion of bordered pits, called aspiration (Liese and Bauch 1967), may occur and inhibit liquid transport between adjacent lumens in the event of rewetting, thus having a significant influence on wood permeability. Sapwood consists in the outer layers of the tree trunk, which are younger and active in the conduction of water. Heartwood, the remaining core of the trunk, is older, non-active in water conduction, and has undergone some maturation. The transformation from sapwood to heartwood involves the aspiration of many pits. Thus, heartwood is known to be significantly less permeable to water than sapwood. As a result of this cellular structure, liquid uptake has a different behavior along the three directions, i.e., radial, tangential and longitudinal, due to the orthotropic cellular structure of wood and several factors, such as species, sapwood versus heartwood, growth rings, pit distribution, further affect the flow of the liquid filling the lumens (Sedighi Gilani et al. 2012, 2014).

In addition to the overhygroscopic region where liquid water fills the lumen, the moisture capacity of wood has also a hygroscopic region where moisture is only absorbed in the nanoporous cell wall. This cell wall is a polymeric composite made of cellulose nanofibril aggregates immersed in a lignin/hemicellulose matrix. The sorption of water molecules in the cell wall results in their swelling and, thus, swelling of wood at the macroscale (Kulasinski et al. 2015). The organization of the nanofibril aggregates within the cell walls as well as 
the arrangement and geometry of the cells themselves explain the orthotropic mechanical and swelling behavior of wood. Sorption and the resulting swelling/shrinkage induced by changes in water content are due to the polar nature of water. Nonpolar liquids due to their nonpolar nature and molecular size may not enter the cell wall, but reside at its surface, and as such may not cause swelling in wood. Nevertheless, differences in their other properties compared to water, such as contact angle and wettability, also affect their uptake in wood. In order to study liquid uptake in wood in the absence of sorption, nonpolar liquid could be used, but only few studies went into this direction. Using different liquids to determine wood density, Stamm (1929) observed that the finer structure of wood, namely of Alaska cedar (Cupressus nootkatensis), Douglas fir (Pseudotsuga menziesii) and Sitka spruce (Picea sitchensis), is not permeable to nonpolar organic liquids. Bailey and Preston (1970) measured permeability at saturation using water and a petroleum distillate to eliminate flow through the cell walls and could thus focus on the role of pits in sapwood versus heartwood of Douglas fir. O'Leary and Hodges (2001) used different mixtures of water/methanol or methanol/xylene to achieve different swelling magnitude of Pinus sylvestris (Pinus sylvestris L.) and found that saturation uptake is dependent on swelling. Zillig (2009) used water and cyclohexane in liquid uptake measurements on Norway spruce in the three directions, finding globally higher and linear coefficients of cyclohexane uptake than for water uptake. Such measurements of the bulk behavior could, however, not provide information on the local distribution of liquids within wood.

In order to examine the influence of water adsorption and its resulting swelling of wood cell walls on liquid transport in heartwood and sapwood, neutron imaging is used in this paper to document the time-dependent and spatial distribution of two liquids, one polar and one nonpolar, during liquid uptake in samples of three softwood species.

\section{Materials and Methods}

\subsection{Materials}

Three species of softwood are considered: Norway spruce (Picea abies), balsam fir (Abies balsamea) and Scots pine (P. sylvestris). These species have similar properties and are widely used in construction. For each species, samples measuring $15 \times 15 \times 5 \mathrm{~mm}^{3}$ were quartersawn with the longitudinal, tangential or radial directions parallel to uptake and so that the growth ring features were visible in the radiograph acquisition plane for each orientation $(X Y$ or detector plane in Fig. 2). The spruce and fir samples were cut out of heartwood, and the pine samples were cut out of sapwood, which is known to have a higher liquid permeability than heartwood. Each sample was first examined using X-ray cone-beam computer tomography (3D-CT) to verify the absence of natural defects or of defects due to preparation or checks. The setup consists of an X-ray source (X-ray tube "XT9225-TEP," Viscom), an XYZ linear stage (composed of three linear stages "LS-270," Micos) for positioning the specimen, a rotation table ("UPR-160 F air," Micos) and an X-ray detector ("XRD 1621 CN3ES," Perkin-Elmer). The X-ray tube was operated at $80 \mathrm{kV}$ and $0.1 \mathrm{~mA}$, and the emitted X-ray spectrum was hardened with a 0.5 -mm-thick $\mathrm{Cu}$ filter. The samples, initially at storage room equilibrium with $50 \% \mathrm{RH}$, were oven-dried one week at $100^{\circ} \mathrm{C}$ and then stored in a desiccator at dry condition, over silica gel particles, prior to the capillary uptake experiments. Although the drying from already low moisture content almost ensures that no further cracking would occur, all samples were visually examined after drying and during imaging, and again after 


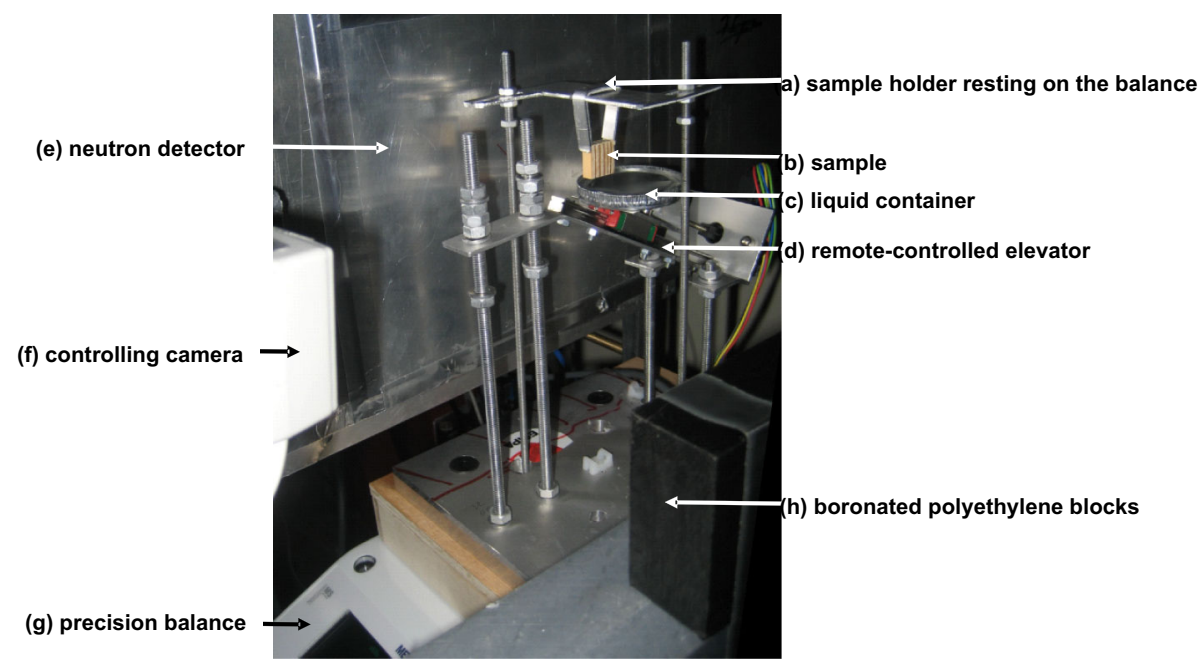

Fig. 2 Experimental setup inside the NEUTRA beamline

the water uptake and subsequent drying, and no crack appearance was found. A normal feature of sample preparation for liquid uptake experiment is to ensure that liquid uptake occurs through the bottom surface area of the specimens and that no liquid film runs on the exterior surface of the sample. This is done by covering or sealing the four vertical sides of the samples. However, as most sealants attenuate neutrons and/or penetrate wood and thus modify the sample contact area with the liquid, all sides of the specimens were left unsealed. To estimate the effect of possible flow from the sides of the unsealed specimens, additional uptake experiments were performed on specimens with their four sides parallel to the uptake direction sealed with paraffin wax, and top and bottom left unsealed. Paraffin wax is hydrophobic and liquid can thus not wet the exterior sides of the samples. It was found that total uptake was in the order of 1.5-10\% greater for the uncoated specimens compared to the sealed specimens. We therefore concluded that the uptake on the surface is sufficiently limited to not influence the uptake beside an edge effect.

To select the nonpolar liquid, preliminary uptake tests were performed using water and five nonpolar liquids to ensure the occurrence of uptake and this absence of swelling (decane, xylene, pyridine, cyclohexane, dibutylamine). Decane $\left(\mathrm{C}_{10} \mathrm{H}_{22}\right)$ was selected as the nonpolar liquid for uptake experiment. Due to its high content of hydrogen, it attenuates neutrons as much as water in neutron radiography. Some physical properties of decane are compared to those of liquid water in Table 1 (NIST; Yaws 1999; David 2009 for the four first column, contact angles are own measured on dry wood). It can be seen that the saturated vapor pressure of decane is low, meaning that it will not vaporize during the 2-h duration of the liquid uptake experiments unlike most of the other volatile nonpolar liquids considered. Decane also has one of the highest densities, surface tensions and viscosities among the nonpolar liquids, making it more similar to water in those respects. Sorption of decane in wood was found to be negligible (Dorris and Gray 1979). Finally, decane is not very toxic. Although it is flammable, the overall characteristics of decane make it a good candidate for this experiment. A main difference is seen for the equilibrium contact angle with wood, which effects will be discussed later. 
Table 1 Some properties of decane compared to liquid water

\begin{tabular}{llllll}
\hline & $\begin{array}{l}\text { Density } \\
(\mathrm{g} / \mathrm{ml})\end{array}$ & $\begin{array}{l}\text { Surface tension } \\
(\mathrm{mN} / \mathrm{m})\end{array}$ & $\begin{array}{l}\text { Viscosity } \\
(\mathrm{mPa} . \mathrm{s})\end{array}$ & $\begin{array}{l}\text { Saturated vapor pres- } \\
\text { sure at } 20^{\circ} \mathrm{C}(\mathrm{mm} \mathrm{Hg})\end{array}$ & $\begin{array}{l}\text { Contact angle } \\
{\left[{ }^{\circ}\right]}\end{array}$ \\
\hline Water $\mathrm{H}_{2} \mathrm{O}$ & 1 & 72.8 & 1.002 & 17.5 & 70 \\
Decane $\mathrm{C}_{10} \mathrm{H}_{22}$ & 0.73 & 38 & 0.92 & 1.4 & 0 \\
\hline
\end{tabular}

\subsection{Experimental Setup}

The liquid uptake experiment setup, which was used at the NEUTRA beamline of the Paul Scherrer Institute (PSI), is custom made, see Fig. 2. The setup has two independent parts: a sample holder resting on a balance and a remotely controlled elevator supporting a liquid container. At the start of the experiment, the sample is placed on the sample holder and the balance (of $0.1 \mathrm{mg}$ accuracy) is zeroed. Blocks of boronated polyethylene (opaque to neutron radiation) shield the balance and elevator against neutron radiation and its possible damaging effects. Reference X-ray and neutron radiographs are first acquired. This reference $\mathrm{X}$-ray is used later for quantification of swelling. Then, the liquid container is moved up until the base of the sample is in contact with the free liquid surface. Following this, neutron radiographies of the specimens are acquired at three frequencies during liquid uptake: at 8-s intervals during this first $5 \mathrm{~min}$, then at 1 -min intervals for $5 \mathrm{~min}$ and finally at 5 -min intervals until the end of experiment, which has a total duration of $135 \mathrm{~min}$. The mass of absorbed liquid is automatically measured by the balance at every $30 \mathrm{~s}$, during each experiment. The exposure time of one radiography is $8 \mathrm{~s}$, and the attained spatial resolution is that of the pixel size, i.e., $85 \mu \mathrm{m}$.

Figure 3 shows the reference neutron radiography of the tested samples, taken before the uptake experiments. Darker colors correspond to higher amount of hydrogen, thus indicating the location of the denser latewood layers.

During uptake, as the base of the sample is immersed in liquid, a water meniscus forms. Due to the high contrast of bulk water, the changes in moisture content of the portion of the sample under the meniscus line cannot be evaluated during uptake from the neutron images. However, this area is documented at the end of the water uptake experiment, after the liquid container has been moved down and the whole area of the sample is visible.

Considering the two liquids, three species and three orthotropic directions, 18 uptake test configurations were documented with neutron radiography. To simplify the comparison of behavior, the same samples were used for water and decane uptake. In the case of tangential decane uptake in fir, the neutron beam stopped $10 \mathrm{~min}$ into the experiment (occasional low proton production at SINQ) and imaging was thus not possible. Despite this, the uptake experiment was left running and the sample weighed at the end of the experiment. To get neutron images of tangential decane uptake in fir, this configuration was retested using a different sample (referred to as sample "b"). Thus, 9 wood samples were tested by being first subjected to uptake of water, then oven-dried for a minimum of $24 \mathrm{~h}$ at $100^{\circ} \mathrm{C}$ and tested again with decane, and an additional wood sample (fir, tangential orientation) was subjected to decane uptake only. In order to demonstrate reproducibility, the uptake experiments were also repeated in laboratory, thus without imaging, on 'twin' samples, i.e., cut side by side out of the same wood plank and location that produced the samples used for imaging. 

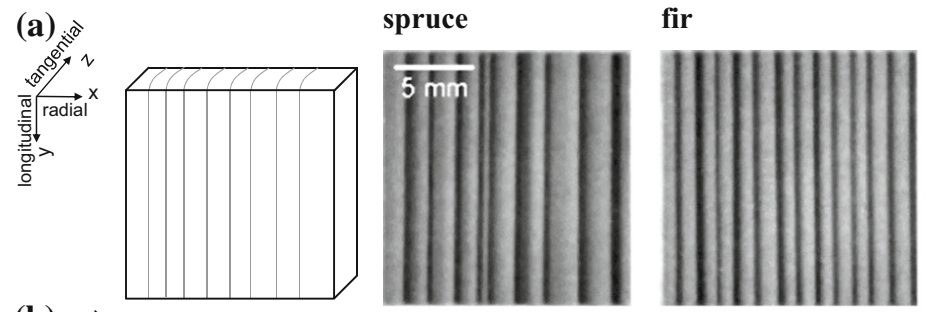

pine-sapwood

(b)
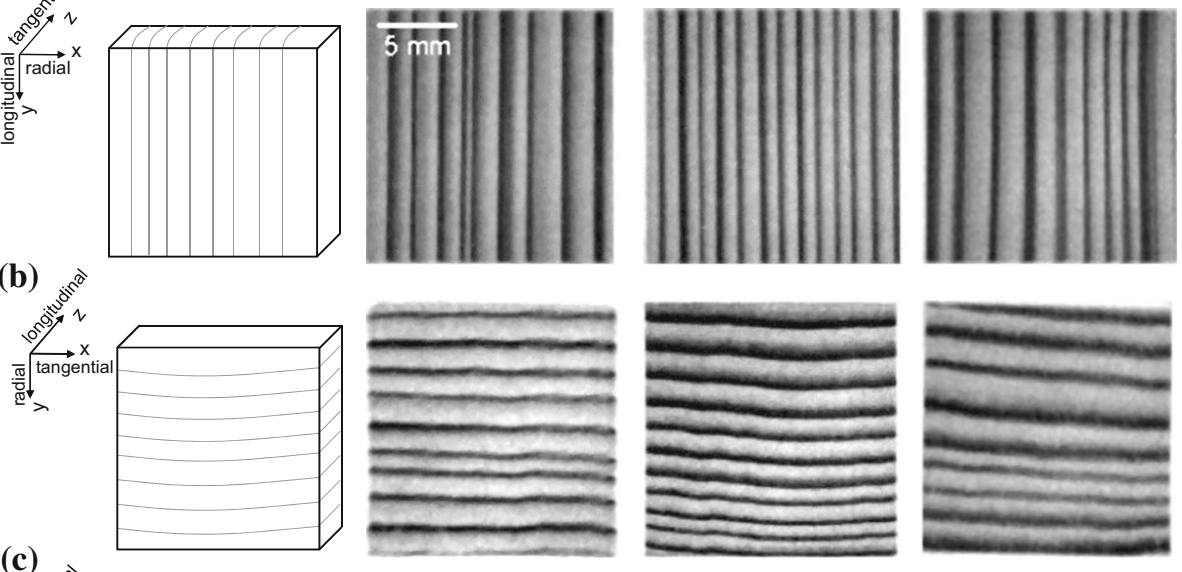

(c)
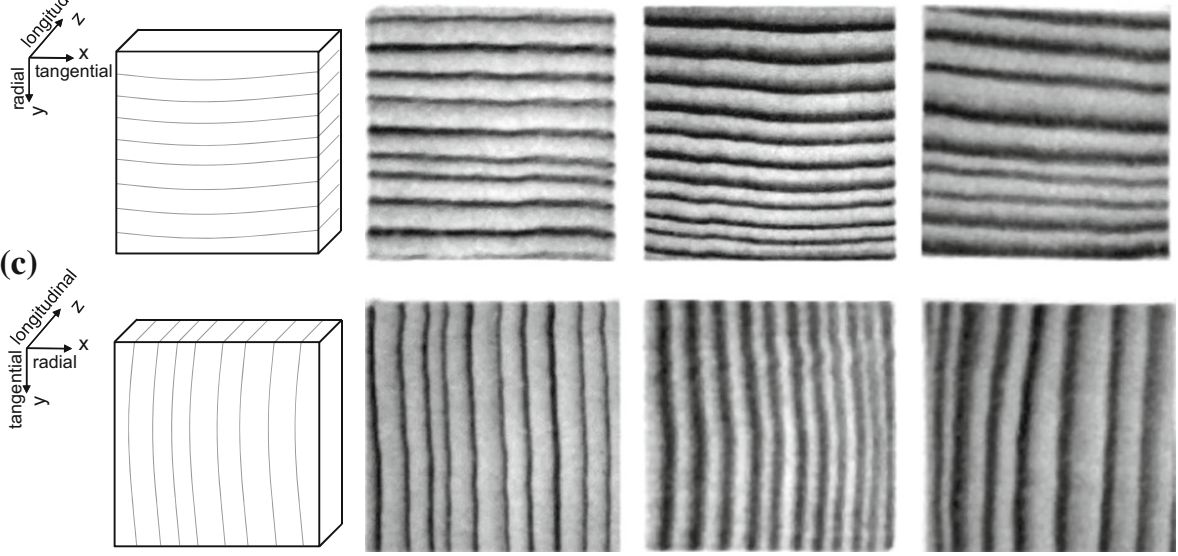

Fig. 3 Reference neutron radiography of spruce and fir heartwood and pine sapwood samples, in the a longitudinal, $\mathbf{b}$ radial and $\mathbf{c}$ tangential directions, taken just before the experiments

\section{Analysis of Neutron Radiographs}

\subsection{Principles for Determination of Moisture Content}

Neutron radiography is based on intensity measurements of a neutron beam transmitted through an object. The beam has a polychromatic energy spectrum; however, Eqs. (1-5) are derived for simplicity for a monochromatic neutron beam. The intensity of the transmitted monochromatic beam, $I$, can be described with Beer-Lambert law:

$$
I=I_{0} \mathrm{e}^{-\Sigma \cdot z}
$$

where $I_{0}$ is the intensity of the incident neutron beam, $z$ is the thickness of the object along the beam direction and $\Sigma$ is the effective attenuation coefficient for neutrons. For compound materials like wood, water or decane, the attenuation coefficients of the individual elements (hydrogen, oxygen, carbon, etc.) determine the total attenuation. We simplify the composition of the tested sample to consist of wood and liquid, water $\mathrm{H}_{2} \mathrm{O}$ or decane $\mathrm{C}_{10} \mathrm{H}_{22}$, using a bilayer approximation (Sedighi Gilani et al. 2012) where, a time $t$, the effect of liquid taken up by wood on the neutron beam attenuation is considered equivalent to the effect of a liquid layer with thickness $z_{l}$ added to the dry wood sample. Implementing this description, Eq. (1) becomes:

$$
I(t)=I_{0} \mathrm{e}^{-\left\{\Sigma_{\mathrm{s}} \cdot z_{\mathrm{s}}+\Sigma_{1} \cdot z_{1}\right\}}
$$

where the subscript $s$ refers to the solid wood and $l$ to the absorbed liquid. At a certain time $t$ during the experiment, with respect to the initial stage, the change in the beam intensity 
comes from the time-dependent change of moisture content, i.e., from the thickening of the "effective" liquid layer. Wood swelling in the direction along the neutron beam has a negligible effect on beam attenuation and Eq. (2) can therefore be written as:

$$
I(t)=I_{\text {dry }} \mathrm{e}^{-\left\{\Sigma_{1} \cdot z_{1}(t)\right\}}
$$

where $I_{\text {dry }}=I_{0} \mathrm{e}^{-\left\{\Sigma_{\mathrm{s}} \cdot z_{\mathrm{s}}\right\}}$ is the intensity of the neutron beam for the dry (initial) sample. Solving for the change in liquid thickness yields:

$$
z_{1}(t)=-\frac{1}{\Sigma_{1}} \ln \left(\frac{I(t)}{I_{\mathrm{dry}}}\right)
$$

Multiplying the effective liquid layer thickness by its density, $\rho_{\mathrm{l}}$, and dividing by the sample thickness, $z$, yield the moisture content $\left(\mathrm{kg} / \mathrm{m}^{3}\right)$.

$$
w(t)=-\frac{\rho_{\mathrm{l}}}{z \cdot \Sigma_{\mathrm{l}}} \ln \left(\frac{I(t)}{I_{\mathrm{dry}}}\right)=\frac{\rho_{\mathrm{l}}}{z \cdot \Sigma_{\mathrm{l}}}\left(\ln I_{\mathrm{dry}}-\ln I(t)\right)
$$

As the densities of water and decane are significantly different, the quantity of uptaken liquid is presented here in volume per cubic meter $\left(1 / \mathrm{m}^{3}\right)$ to allow comparison. Thus, the liquid content is divided by the density of different liquids to obtain the uptaken volume of liquid by volume of material. At the outset, each raw neutron radiograph is corrected for artifacts. These corrections are standard procedures common to all radiation transmission-based imaging methods and include dark current correction for the background noise of the CCD camera, open beam correction for temporal and spatial fluctuations of the incident beam, black body correction for removing the neutron signal coming from scattering by the overall experimental configuration, sample scattering correction for neutrons that are scattered by the atoms of the wood/liquid of the sample itself and reach the detector and, finally, correction for taking into account the beam polychromatic energy spectrum. To correct for the scattered neutron signals on the detector, we used the quantitative neutron imaging (QNI) algorithm, developed by Hassanein (2006), which is based on the iterative reconstruction of the measured image by overlapping point scattered functions calculated by means of Monte Carlo simulation. A quantification based on uncorrected radiographs would result in an underestimation of the water content, up to $50 \%$, compared with corrected radiographs (Hassanein et al. 2005). Correction with QNI was sufficient to bring the total mass difference measured by balance and from neutron imaging within $<10 \%$ from each other.

\subsection{Determination of Swelling}

Swelling occurs in all three orthotropic directions of wood, more importantly in the tangential than in the radial directions and almost insignificantly in the longitudinal direction. While the specimens expand during water uptake, the time-resolved change in the geometry of specimen is documented with NR images. Swelling along the $x$-direction of the acquisition plane is determined as:

$$
\varepsilon_{x}(y, t)=\frac{L_{x}(y, t)-L_{x}\left(y, t_{0}\right)}{L_{x}\left(y, t_{0}\right)}
$$

where $\varepsilon_{x}(y, t)$ and $L_{x}(y, t)$ correspond with the time-dependent swelling strain and the dimension of the specimen, both along $x$-axis at height position $y$ and time $t$. In each image, the swollen area of the sample in the $2 \mathrm{D}$ plane is measured after segmentation from the background, using Otsu's method (Otsu 1979). Further, using the TurboReg plugin in ImageJ (Thévenaz et al. 1998), the full registration of the images allows the subtraction as per Eq. (5). Thus, uptaken volumes of liquid are given per volume of dry wood. 


\section{Experimental Results and Discussion}

In this section, we first compare the process of capillary uptake of the polar and nonpolar liquids over time by the different wood samples. We then discuss the two-dimensional spatial distribution of both liquids within the samples at specific time steps, followed by the profiles of liquid uptake and of swelling along the sample height.

\subsection{Liquid Uptake Versus Time}

Figure 4 presents the total volume of uptaken water (left) and decane (right) versus time (top row) and versus square root of time (bottom row) for one sample: spruce, in tangential direction. The thick black lines with circular markers indicate the volume of liquid determined from individual neutron radiographs, using Eq. 4 for determining local moisture thickness and integrating over the whole surface of the sample. The values measured in situ with the precision balance during the neutron radiography are represented by the dark continuous lines. The two dashed lines are the results from the two repeat experiments with a precision balance in the laboratory on twin samples, as mentioned in the Materials and Methods section.

The agreement between the total liquid volume determined from the neutron images and the values measured in-situ with the precision balance during the neutron radiography shows the accuracy of the liquid uptake quantification from the neutron radiographies. The results of the experiments replicated in laboratory display the same global behavior, with very similar slope, thus rate of uptake, although some offset is observed. The differences of actual liquid content, at the same time between the twin samples, may originate from the natural heterogeneities in wood. The repeats of the uptake experiments validate the liquid
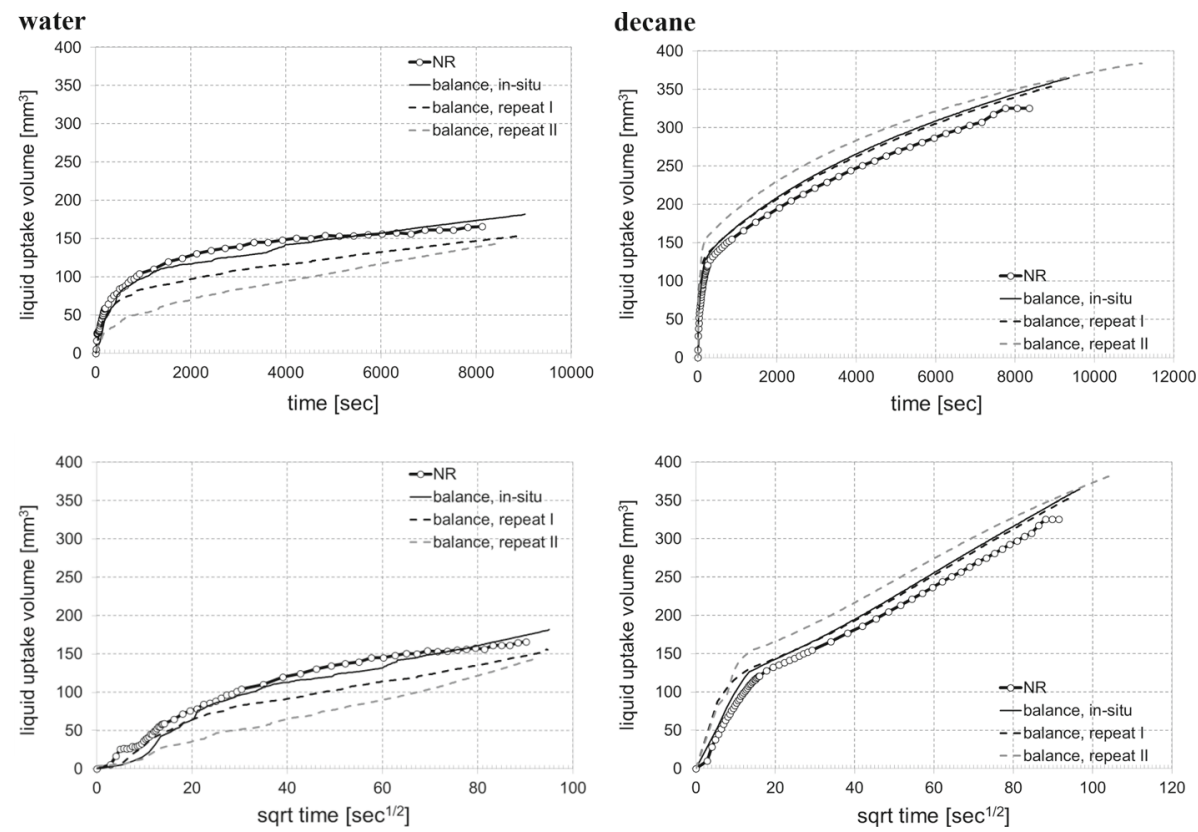

Fig. 4 Spruce liquid uptake along tangential direction versus time (top) and versus square root of time (bottom), for water uptake (left) and decane uptake (right) 
determination procedure from the neutron images and demonstrate the reproducibility of the experimental procedure.

The curves plotted versus time, top row of Fig. 4, show that the initial liquid uptake is very fast and that it then slows down. Plotting the curves against the square root of time, as shown in the bottom row of Fig. 4, clarifies the process of the first minutes of the uptake. The slope of the water capillary uptake curve considered in square root of time for homogeneous, isotropic, non-swelling porous media is known to be linear (Philip 1957; Gardner and Mayhugh 1958). This is not what is seen here for wood, which is orthotropic and swells with water uptake. On the other hand, this same cellular structure under decane uptake displays a very linear behavior passed the first few minutes of the test, which indicates that the nonlinearity of the water uptake may be dependent on water sorption by the cell walls.

We then compare liquid uptake for the $18+1$ tests performed with imaging, thus water and decane uptake, in samples of spruce, fir and pine cut in the three orthotropic directions. In Fig. 5, the total volume of uptaken liquid as determined from the neutron radiographs for spruce, fir and pine in the longitudinal, radial and tangential directions is plotted versus the square root of time. The following hollow markers are used for the different species: circular for spruce (dark gray), triangular for fir (light gray) and lozenges for pine sapwood (black). For clarity, the 1-, 7-, 30- and 135-min time steps, used as benchmarks for the discussion, are shown on each graph. The results for decane tangential uptake in the additional fir specimen "b" are also presented using gray-filled triangular markers.

\subsubsection{Results and Discussion}

Decane uptake mostly displays two linear slopes. In the first few minutes of the experiment, uptake of decane is very fast. Decane uptake then slows down, before the 7-min mark for most cases, and becomes linear with square root of time. On the other hand, water uptake starts more slowly, but then displays a linear or nonlinear behavior versus square root of time, depending on the species and orientation considered. The difference between water and decane uptake in terms of volume of liquid is more pronounced for spruce and fir heartwood than for pine sapwood.

Spruce and fir mostly display similar liquid uptake behavior (Fig. 5a, b), except in the tangential direction, where both water and decane uptake are higher for fir than for spruce at the end of the experiment (Fig. 5c). On the other hand, the second fir sample in decane uptake displays a behavior similar to the one of spruce (Fig. 5c, right). Both water and decane uptakes are always faster and higher for pine sapwood, for all orientations.

Despite decane uptake being generally faster in the beginning, after $30 \mathrm{~min}$ into the experiments, the volumes of water for longitudinal uptake in fir and pine sapwood (Fig. 5a) are larger than those of decane. And at the end of the experiment, the volume of water is larger for all species in this direction.

While the water uptake process is somewhat similar in the longitudinal and tangential directions for spruce and fir (Fig. 5a, c, left), radial water uptake is significantly slower for these heartwood samples (Fig. 5b, left). In comparison, radial decane uptake for these samples (Fig. 5b, right) is much higher, and no such large difference between the orientations can be seen for decane uptake. Decane uptake is actually fastest in the radial orientation for both spruce (heartwood) and pine (sapwood), while the longitudinal orientation shows the slowest decane uptake for all wood species.

The faster initial uptake of decane can be partly attributed to its higher wettability and low contact angle compared to water. The shapes of the water versus decane uptake curves also 

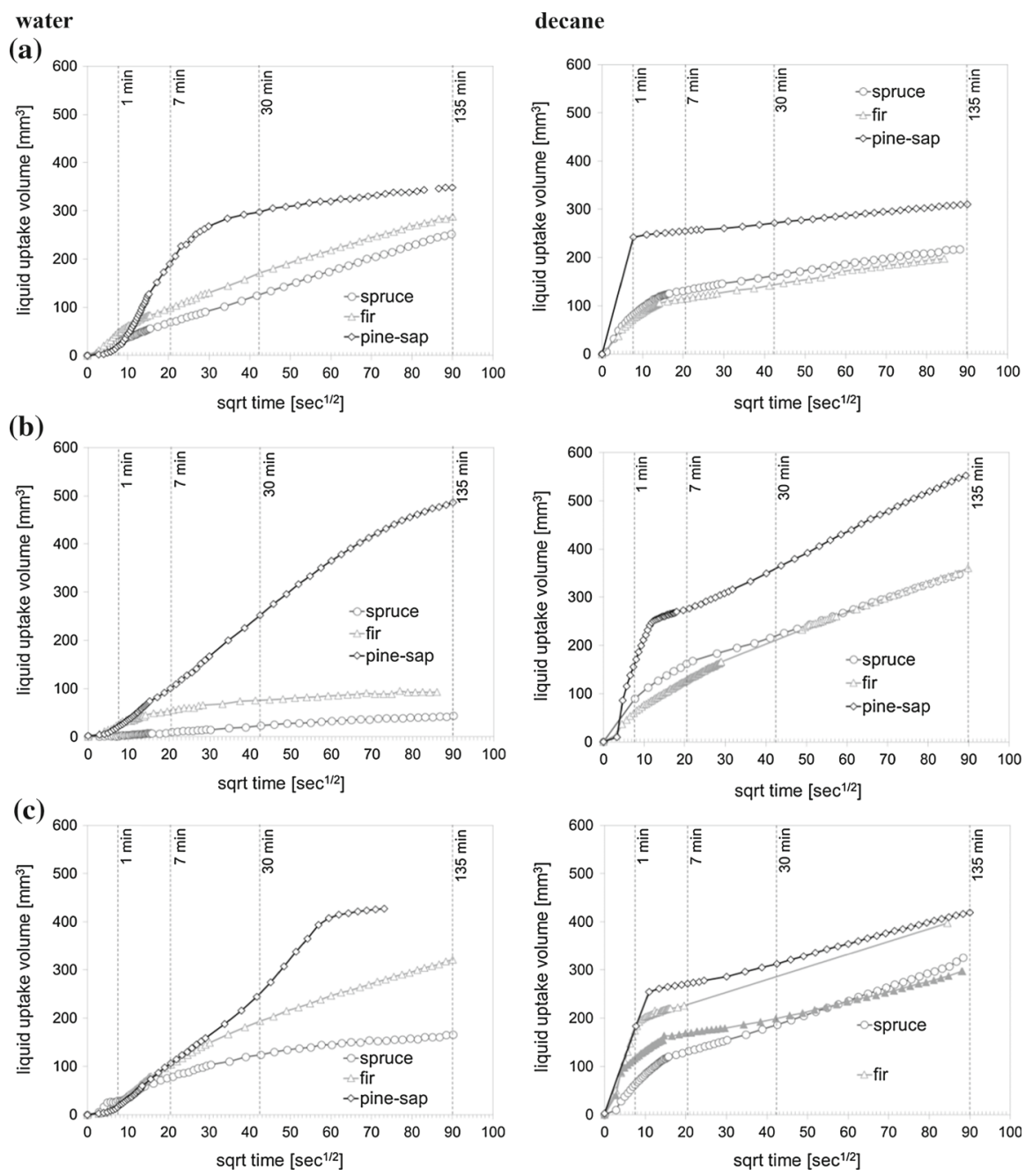

Fig. 5 Water (left) and decane (right) uptake in spruce, fir and pine sapwood along the a longitudinal, $\mathbf{b}$ radial and $\mathbf{c}$ tangential directions

indicate that, although the volume of liquid may be similar at the end, the uptake processes for these liquids are different.

The slight difference between the slopes of the uptake curves of spruce and fir samples, both from heartwood, suggests that liquid flow encounters similar resistances along each of the orthotropic directions for these two species and therefore that their structure is similar. The larger quantity of liquid uptaken by pine sapwood in all directions can be explained by the fact that this type of wood has not undergone the maturation into heartwood, which is known to reduce permeability.

From Fig. 5, we deduce that, in addition to the wettability of the liquid and the wood morphology at the microscale, other parameters, like water sorption within the cell wall and the resulting swelling, are also involved in the uptake process. 


\subsection{Spatial Distribution of Liquid}

Temporal 2D plots of the volume of uptaken liquid for each pixel (units are liters per cubic meter, $1 / \mathrm{m}^{3}$ ) along the longitudinal, radial and tangential orientations are presented in Figs. 6 , 7 and 8 , respectively. These plots show the spatial distribution of the liquids during the uptake experiments at 1,7,30 and finally at $135 \mathrm{~min}$, at the end of the experiments.

Each figure shows volume distribution plots for (a) spruce, (b) fir and (c) pine sapwood, with the top row plots being for water uptake and the bottom row plots for decane uptake. The reference neutron radiographies of the samples are shown in Fig. 3. The dashed lines correspond to the level of the liquid surface, meaning that the sample was immersed in liquid below this line. The last image of each series shows the liquid distribution over the whole sample, based on the neutron radiograph taken at the end of the experiment, just after the liquid container was lowered (except for longitudinal water uptake in pine and radial water uptake in spruce, for which no image with the liquid container lowered is available). The scale used in the images is presented at the right of the image sequences. It goes from blue (smaller volume of liquid) to magenta (larger volume of liquid).

The volume maps in Figs. 6, 7 and 8 illustrate that, in all cases, the liquid front advances in a discrete manner, resulting in high spatial variations of volume of uptaken liquid within the samples. This spatial variation is clearly related to the location of earlywood and latewood layers. Looking at these two-dimensional plots, the difference between the water and decane uptake is significantly more pronounced in the radial and tangential directions (Figs. 7 and 8 , respectively), where a liquid faces more resistance compared to what it encounters in the longitudinal direction (Fig. 6).

\subsubsection{Results and Discussion}

In the longitudinal orientation, see Fig. 6, water first slowly accumulates in specific positions, preferentially at the bottom and in the latewood layers, then moves up, mainly through the latewood layers, and eventually redistributes into the earlywood layers. The spruce and fir heartwoods have quite similar moisture accumulation patterns. In pine sapwood, accumulation at $1 \mathrm{~min}$ is similar to spruce and fir, but after $7 \mathrm{~min}$, water has already reached the top of the sample. From then on, it starts to distribute throughout the sample, including in the earlywood layers. Comparatively, decane has reached the top of all samples through preferential paths, i.e., the latewood layers, by the 7-min mark, resulting in their faster wetting. Decane also distributes more evenly throughout the samples following this early liquid uptake to the top. This decane uptake pattern applies to all three species, but is faster for pine sapwood.

In Fig. 7, radial water uptake is very slow for spruce and fir, with accumulation of moisture mainly in the growth rings close to the liquid surface, and with higher, but still low, volumes at the growth ring interface. Even after $135 \mathrm{~min}$, the maps for these samples show no to very low water uptake. In contrast, radial water uptake in pine sapwood is actually similar to radial decane uptake, although it is somewhat slower. Decane moves up quickly, layer by layer, showing some staircase jumps between growth rings. After $7 \mathrm{~min}$, decane has already reached the top of the samples. It then continues to redistribute. At the end of the experiment, the earlywood layers have uptaken more decane than the latewood layers. Pine sapwood displays very high volumes of decane over all its surface at the end of the decane uptake experiment, compared to spruce and fir heartwood, which still have some regions with lower decane volumes, namely the lower density earlywood. However, this difference between heartwood and sapwood radial for decane uptake is not as important as that seen for radial water uptake. 

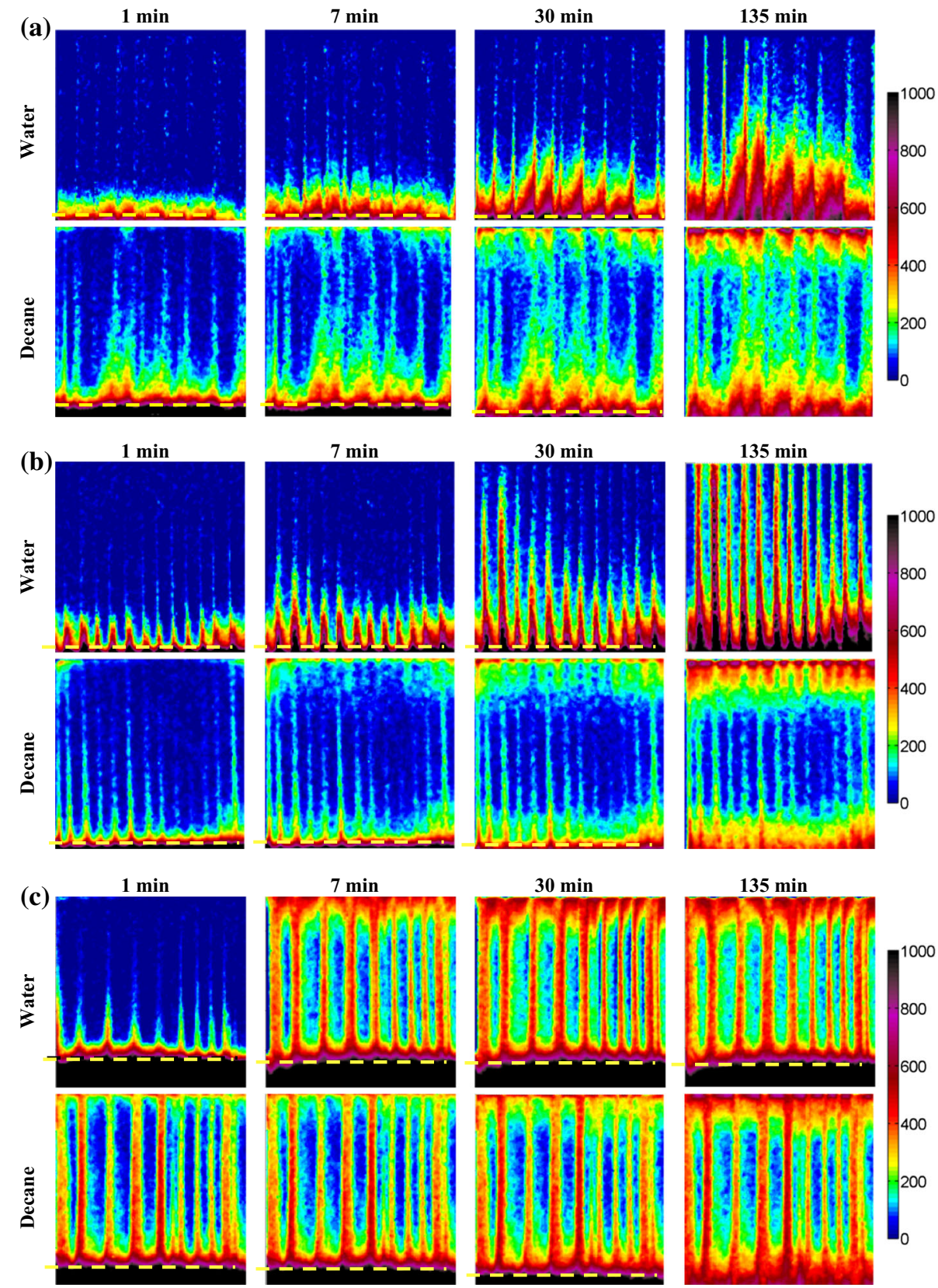

Fig. 6 2D plots of water (top) and decane (bottom) volume (in $1 / \mathrm{m}^{3}$ ) during uptake along the longitudinal direction for a spruce, $\mathbf{b}$ fir and $\mathbf{c}$ pine sapwood

During tangential uptake shown in Fig. 8, there is water accumulation close to the liquid surface and higher volumes are seen in the latewood, compared to earlywood layers. During the tangential water uptake experiments, the two heartwood samples display significantly 

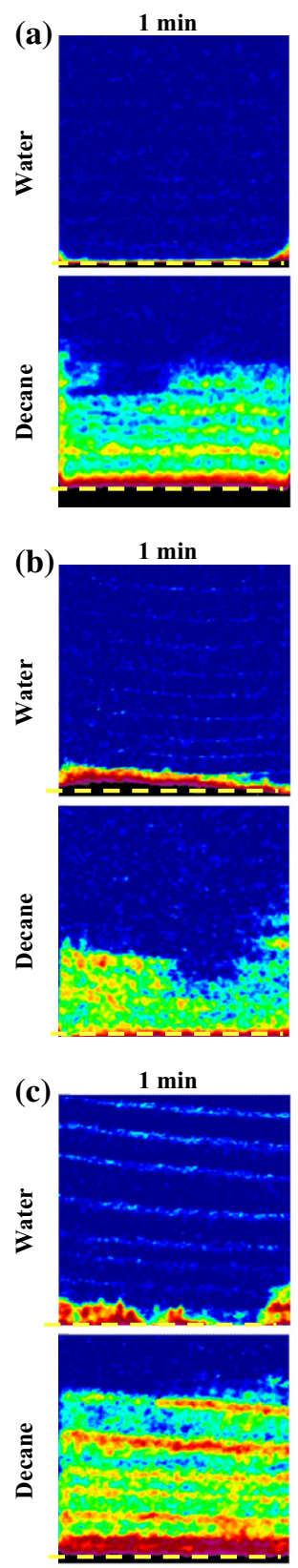

$7 \mathrm{~min}$
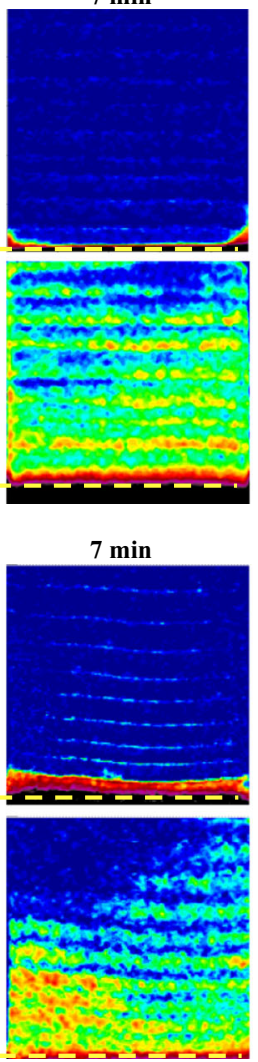

$7 \mathrm{~min}$
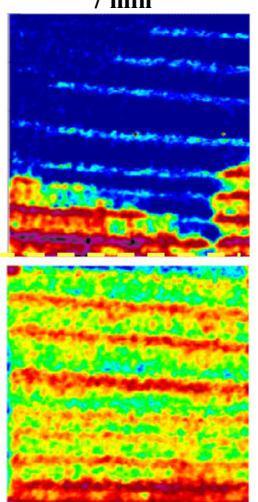

$30 \mathrm{~min}$
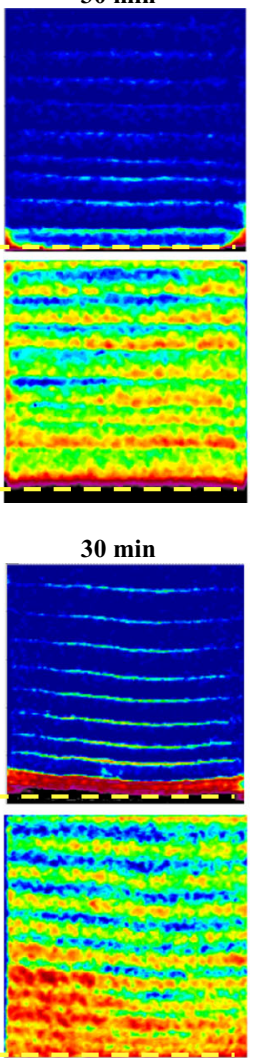

$30 \mathrm{~min}$
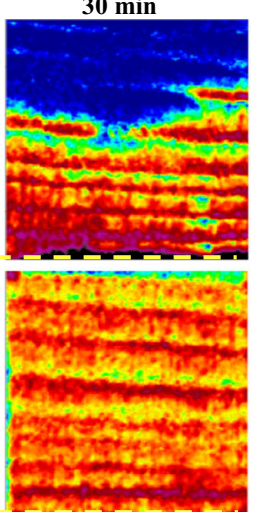

\section{$135 \mathrm{~min}$}

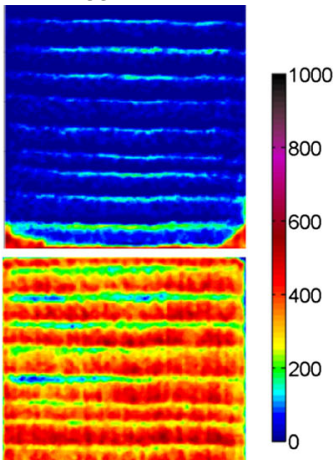

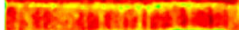

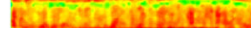
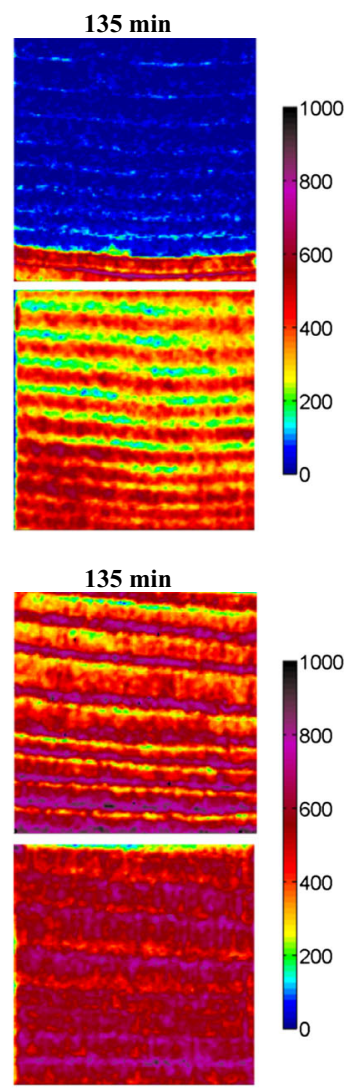

Fig. 7 2D plots of water (top) and decane (bottom) volume (in $1 / \mathrm{m}^{3}$ ) during uptake along the radial direction for a spruce, $\mathbf{b}$ fir and $\mathbf{c}$ pine sapwood

different behaviors: water volumes remain extremely low until the end in the spruce sample, whereas higher water volumes can already be seen in the bottom half of the first fir sample ("a") after $7 \mathrm{~min}$, and almost to the top after $135 \mathrm{~min}$. In the pine sapwood sample, water has progressed already substantially by $7 \mathrm{~min}$ and high volumes of water can be seen over the 

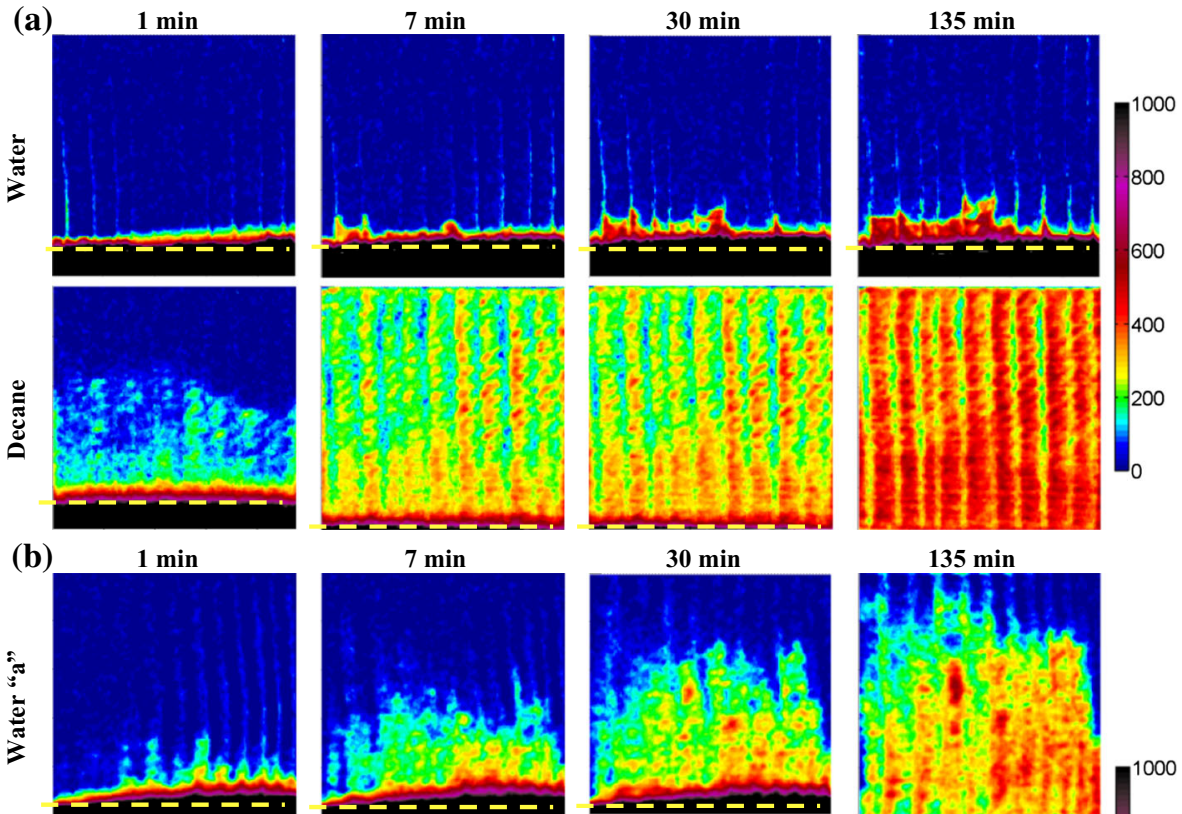

$30 \mathrm{~min}$

$135 \mathrm{~min}$
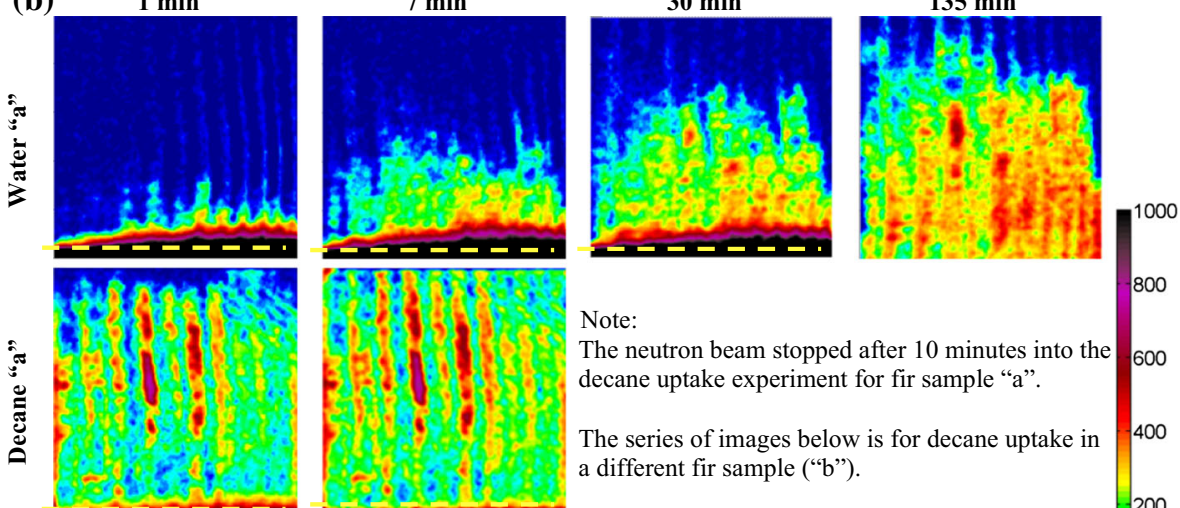

Note:

The neutron beam stopped after 10 minutes into the 600 decane uptake experiment for fir sample "a".

The series of images below is for decane uptake in a different fir sample ("b").
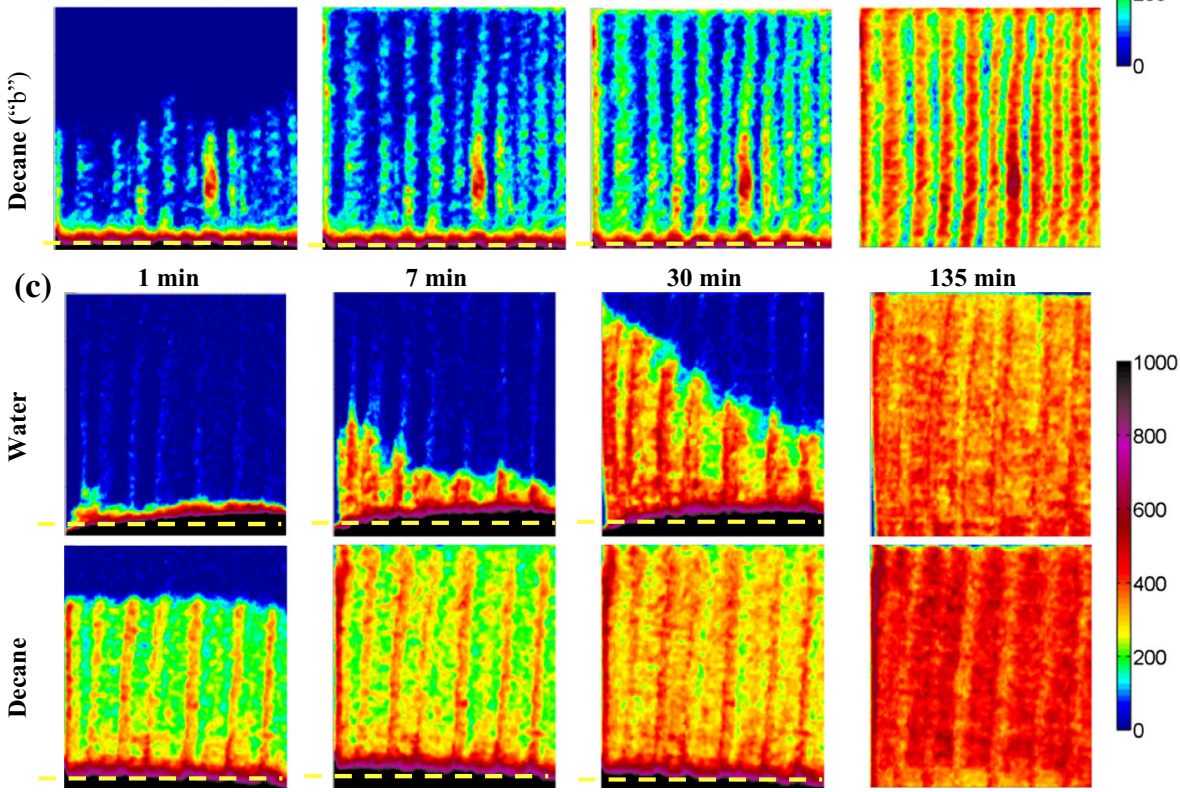

Fig. 8 2D plots of water (top) and decane (bottom) volume (in $1 / \mathrm{m}^{3}$ ) during uptake along the tangential direction for a spruce, $\mathbf{b}$ fir and $\mathbf{c}$ pine sapwood 
whole area of this sample at the end of the experiment. Figure 8 (bottom rows) shows that decane moves up through latewood cells first. After $7 \mathrm{~min}$, decane has already reached the top of all samples, after which it continues to accumulate in the earlywood. It is interesting to note the difference in behavior between the two fir samples subjected to tangential decane uptake. Although only two maps could be produced for fir sample "a" due to an interruption in the neutron beam, it can clearly be seen that its permeability is much higher than for fir sample "b".

In the longitudinal direction, the tracheids are oriented parallel to the direction of uptake. Liquid can therefore move up through the lumens, as well as pass from cell to cell through the pits. The faster uptake in latewood for both liquids can be explained by the smaller diameter of the cell lumens, leading to higher negative capillary pressures in accordance with the Young-Laplace equation. During longitudinal water uptake, the accumulation observed at the bottom of the sample is actually water being adsorbed in the cell walls of all species. During decane uptake, there is no adsorption in the cell wall and decane moves through the latewood tracheids and then quickly redistributes through other paths, such as pits and ray cells. Water and decane uptake are faster in pine sapwood than in spruce and fir heartwood possibly because more of the pits in sapwood remain open, making it more permeable. The similar wetting patterns observed for spruce and fir show that these two species have a similar structure in the longitudinal direction.

In the radial direction, growth rings are oriented perpendicularly to the uptake and ray cells are the only cells oriented in the direction of uptake. The local higher water concentrations observed at the interface between the growth layers for radial water uptake could be attributed to the interruption of ray cells at this interface, corresponding to the dormant period in the tree growth. During radial decane uptake, water moves from growth ring to growth ring through the crossfield pits of the ray cells. In the end, earlywood generally holds higher volumes of liquid.

In the tangential direction, both the longitudinal cells and the ray cells are oriented perpendicular to the uptake direction. Thus, liquid transport can only occur by crossing the lumens and through the pits between different cells. In Fig. 8, the observed preferential uptake in latewood could be explained by the known higher percentage of open bordered pits in latewood compared to earlywood, induced by the higher rigidity of the pit membranes in latewood, which prevents the aspiration of pits during drying from green state and reduces permeability (Siau 1984; Almeida et al. 2008). For the spruce heartwood sample, the fact that most of the water accumulates close to the surface, while water volumes remain very low over the rest of the sample throughout the experiment implies that the cell walls close to the liquid surface adsorb water and also that bordered pits, and even more so the crossfield pits, offer a large resistance to the passage of water. The fir sample displays a much higher tangential water uptake than the spruce sample. Pine sapwood displays a much lower resistance to the passage of water, as in sapwood more pits are known to be open. In contrast to spruce and fir, decane distributes faster and much more homogeneously within pine, after initial uptake in latewood.

The difference in behavior between the two fir samples may be explained by the natural heterogeneity of wood. The properties of the liquids also play an important role. Water adsorbed by the cells walls causes swelling, while decane, not adsorbed by the cell wall, does not. The adsorption of water in the cell walls and the swelling slow down the uptake process, but eventually there is a larger of volume of water than decane uptaken. Finally, although pits offer resistance to the passage of water, the very low contact angle and high wettability of decane compared to water could explain that decane seems to be able to flow through any opening or path available more easily than water does. 


\subsection{Liquid Volume and Swelling Profiles}

Figures 9, 10 and 11 present the water (top row) and decane (middle row) volume profiles, as well as the swelling profiles during water uptake (bottom row), plotted over the height of the spruce (left graphs), fir (center graphs) and pine (right graphs) specimens along the longitudinal (Fig. 9), radial (Fig. 10) and tangential (Fig. 11) directions. Swelling profiles are
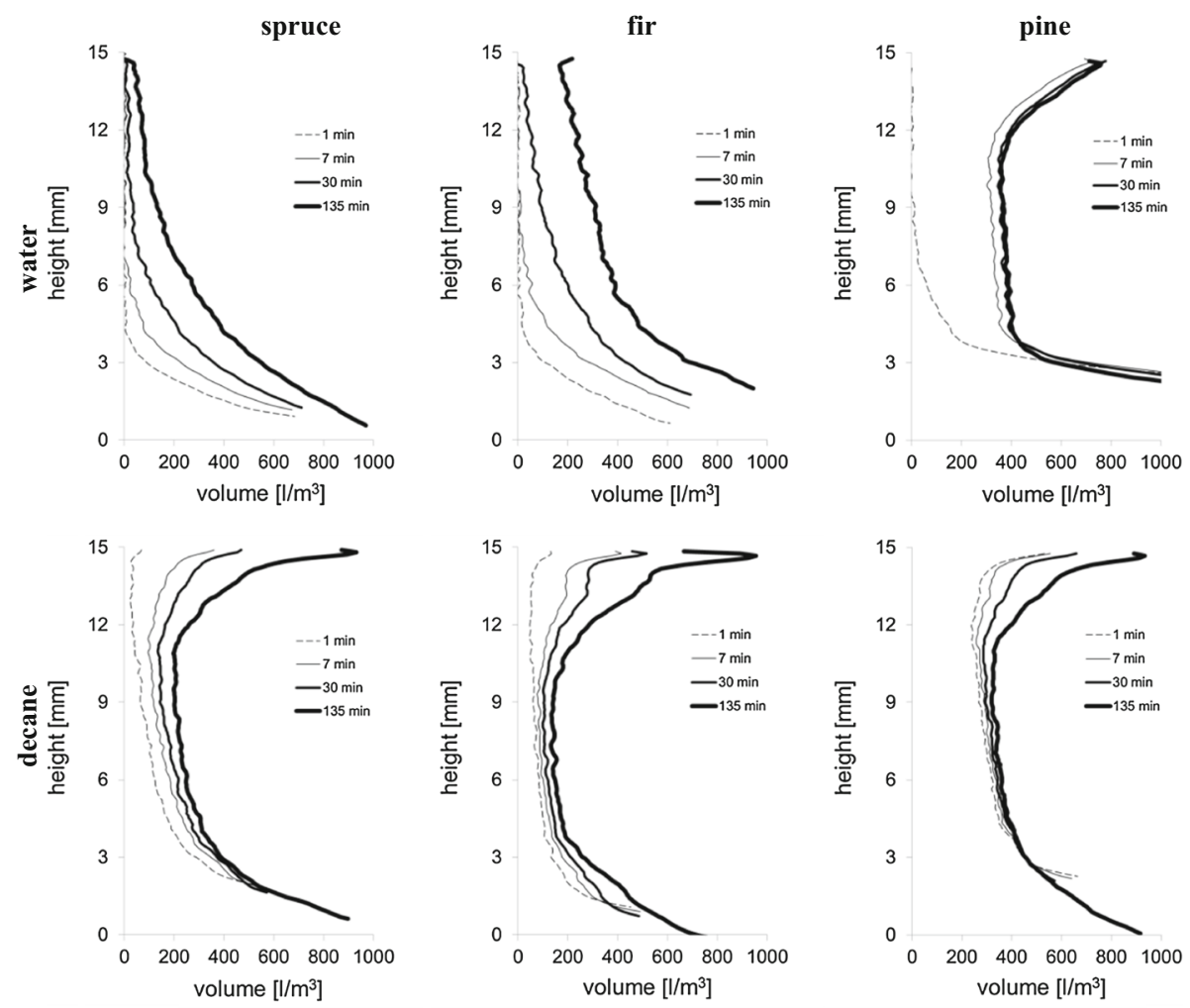

Spruce

Fir

Pine
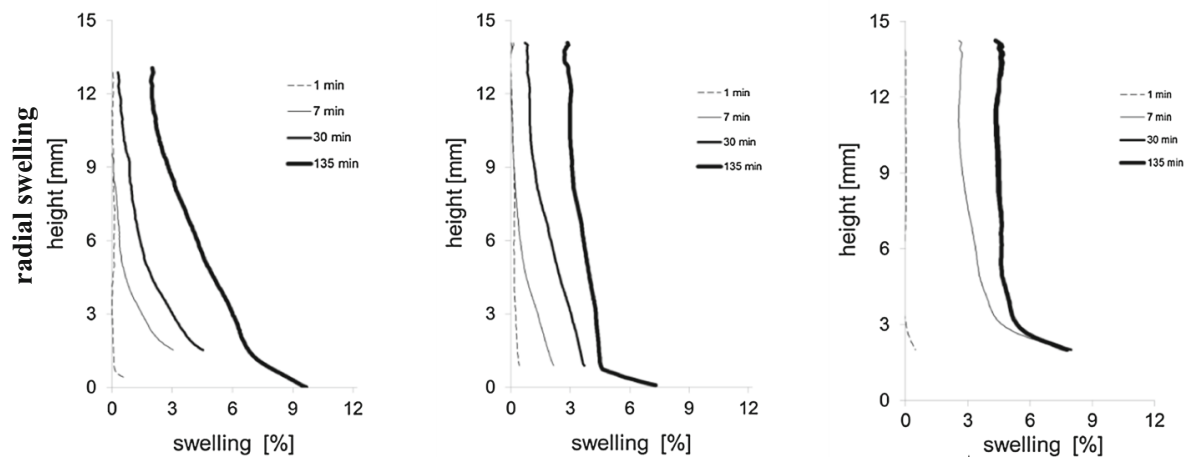

Fig. 9 Water (top) and decane (middle) uptake profiles along the longitudinal direction (in $\mathrm{nl}^{3}$ ), and radial swelling profiles (bottom) for spruce, fir and pine sapwood 

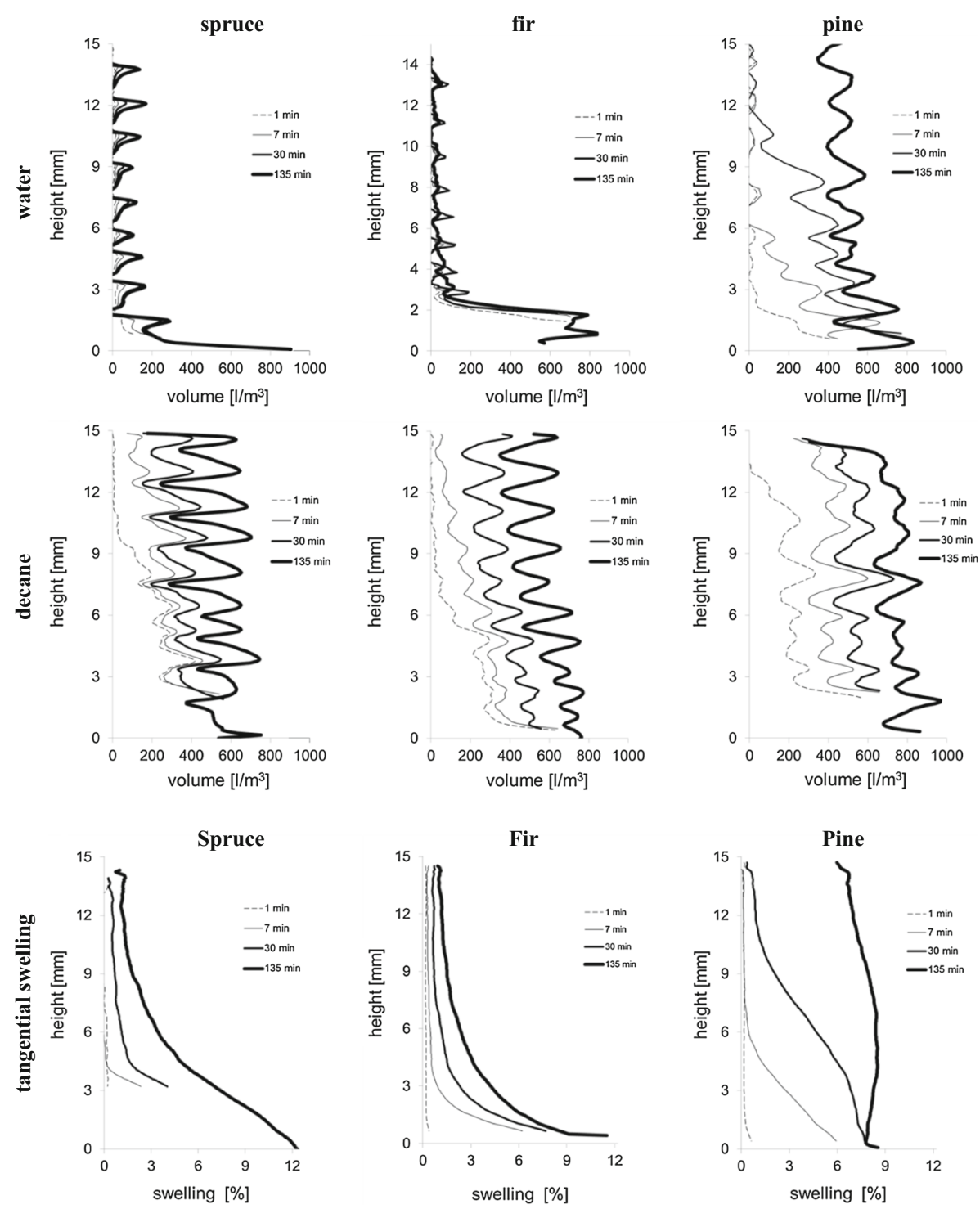

Fig. 10 Water (top) and decane (middle) uptake profiles (in $\mathrm{nl}^{3}$ ) along the radial direction, and tangential swelling profiles (bottom) for spruce, fir and pine sapwood

generated for water only because decane causes no swelling. Profiles are plotted at 1, 7,30 and $135 \mathrm{~min}$ into the experiment. In the volume profiles, the values at specific heights represent the average liquid volume for the width of the sample at that height in liters per cubic meter $\left(1 / \mathrm{m}^{3}\right)$. The swelling profiles are generated along the $x$-axis of the data acquisition plane. Thus, radial swelling is plotted during longitudinal uptake, tangential swelling during radial uptake and radial swelling during tangential uptake. As volume or swelling profiles cannot be plotted for the portion of the specimen immersed in liquid, which portion was not always 

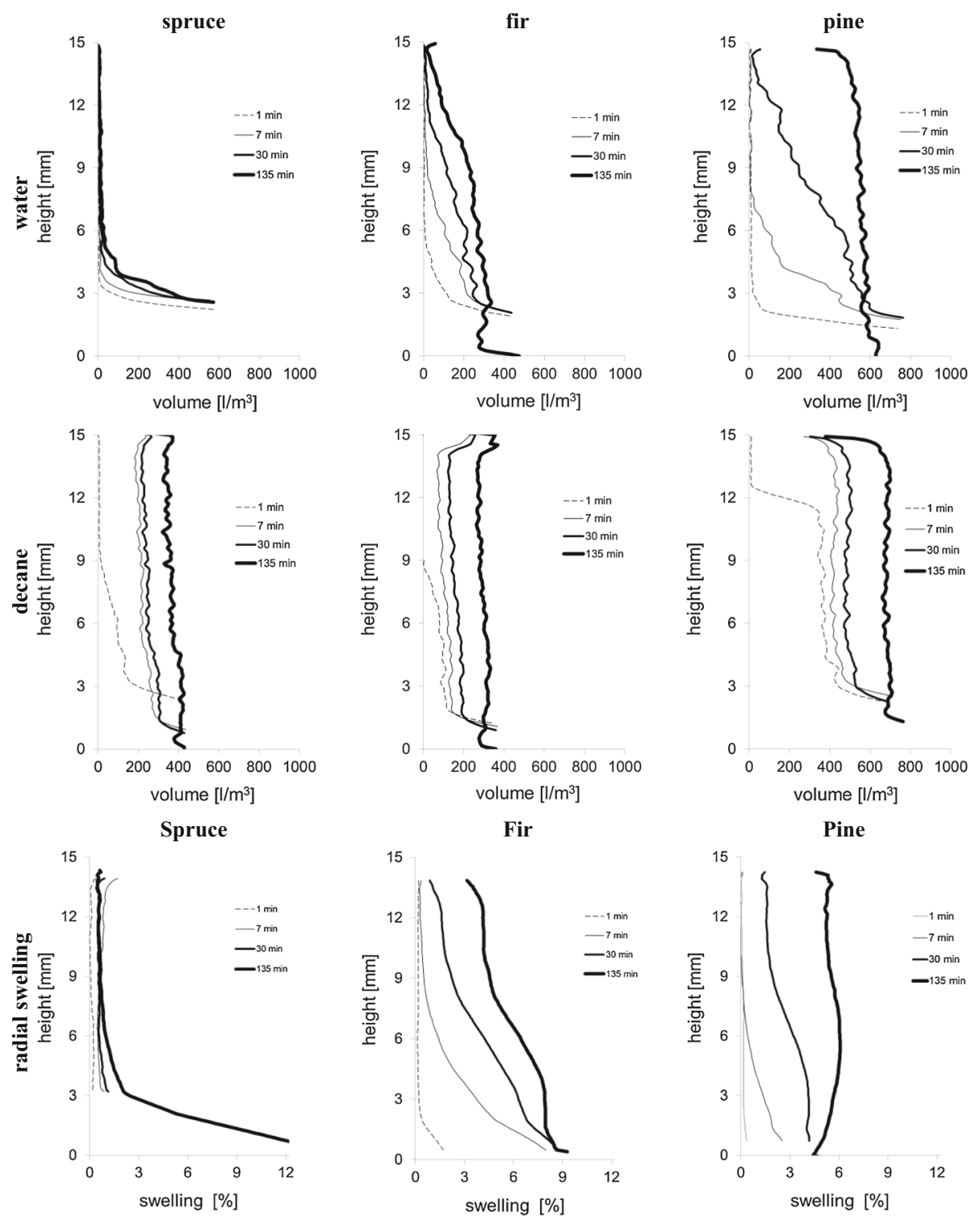

Fir
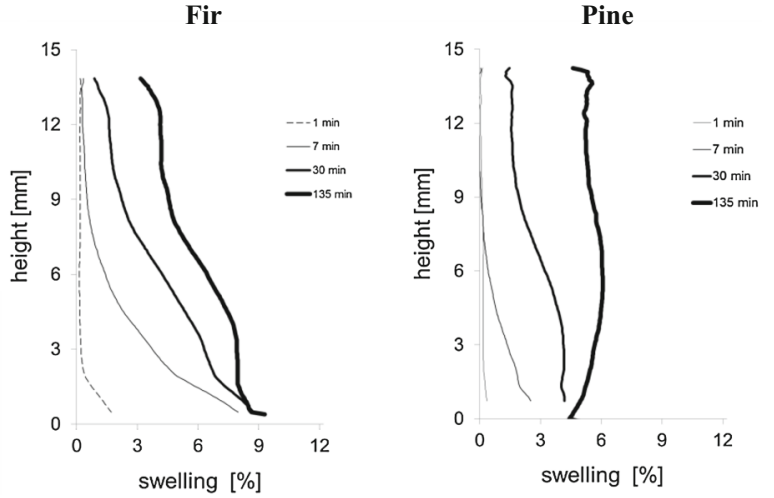

Fig. 11 Water (top) and decane (middle) uptake profiles (in $\mathrm{nl}^{3}$ ) along the tangential direction, and radial swelling profiles (bottom) for spruce, fir and pine sapwood

maintained constant, the profile curves do not necessarily start at the bottom of the specimen, except for the profiles at $135 \mathrm{~min}$, after the liquid tray had been lowered.

\subsubsection{Results and Discussion}

In Fig. 9, the longitudinal water uptake volume profiles for the two heartwood species are similar, showing a strong vertical gradient—-from high at bottom to low at top—and a steady 
increase in water volume during the experiments. A different type of profile is seen for pine sapwood: although the 1-min profile is similar to those obtained for the heartwood species, by $7 \mathrm{~min}$ higher volumes are seen at the top and bottom of the sample than in the middle, resulting in $\mathrm{C}$-shape curves from that point on. There is a significant water volume increase between the 1- and 7-min time steps, but then no significant change is seen between the profiles at 7, 30 and $135 \mathrm{~min}$, especially the 30 and $135 \mathrm{~min}$ profiles, which overlap.

The C-shape curve pattern is seen for all three species during longitudinal decane uptake. However, the initial increase in decane volume is faster in pine sapwood, particularly in the center and top portions of the sample, compared to a more gradual increase for spruce and fir. Decane volumes in the top portion increase throughout the experiment for all samples. Volumes also continue to increase in the center for the heartwood samples, whereas the decane volume profile curves are closer together at the bottom and center for the pine specimen. In the case of pine sapwood, decane and water volume profiles for the longitudinal orientation are similar, except for the initial water uptake and the more gradual increase in decane volume at the top. After $135 \mathrm{~min}$, the water and decane volume profiles are quite similar in terms of shape and volumes reached. This $\mathrm{C}$-shape pattern would indicate wetting by spreading of a film on the top surface and then a supplementary wetting from above.

In terms of swelling, none of the samples subjected to longitudinal water uptake show significant swelling at the 1-min time step. For the spruce and fir sample, the following time steps show a gradual swelling from bottom to top. The swelling for spruce and fir are in the same range, although the spruce sample shows a stronger vertical gradient and larger swelling at the bottom, compared to the fir sample. For pine sapwood, swelling is initially slow followed by more abrupt swelling compared to the heartwood samples. Swelling in pine appears to reach some maximum, similar to what was seen with water uptake. Also similar to water uptake behavior is the fact that swelling is eventually more uniform for pine sapwood than for the heartwood species. Comparing the longitudinal water uptake and swelling profiles indicates that the adsorption of water in the cells walls is followed by swelling, which is naturally proportional to the water volume.

In Fig. 10, the volume profiles for radial water uptake show clear peaks at the interface between earlywood and latewood. The increase in water volume in spruce occurs at those locations, while for fir, at $135 \mathrm{~min}$, water volumes have increased slightly in earlywood. For both species, water volumes remain very low except at the bottom, close to the water surface. For pine sapwood, water volume profiles develop quite differently. At the 1-min time step, there is only water at the bottom. At 7 and $30 \mathrm{~min}$, water volumes increase for the bottom half of the sample toward the top and peaks develop. At $135 \mathrm{~min}$, high volumes are reached for the whole height of the sample with dented profile and no significant vertical gradient (i.e., volumes at bottom are in the same range as volumes at top).

In Fig. 10, the decane volume uptake profiles in the radial direction are all quite similar for the heartwood and sapwood samples. Decane volumes first increase in the bottom half of the sample for spruce and fir, and over almost the whole height for pine sapwood. Then, decane moves up and volumes increase over whole height of all samples. In heartwood, the peaks develop and get more pronounced as the experiments progress and volumes increase. For pine sapwood, the peaks have more or less the same amplitude at 7 and $30 \mathrm{~min}$ and reduce slightly by $135 \mathrm{~min}$.

During radial water uptake, there is initially no swelling, except for a slight deformation at the very bottom, for all species. Then, there is gradual swelling, from the bottom up, for the two heartwood samples. For pine sapwood, from $7 \mathrm{~min}$, there is fast swelling from the bottom up until the whole sample is swollen, with a slight bulge in the middle. 
In Fig. 11, the tangential uptake water profiles are quite different for the three species. In spruce, water volumes remain close to nil until the end, except in the lower portion of the specimen. For fir sample "a," water volume increases are seen over the whole height of the sample, with a vertical gradient remaining throughout the experiment. For pine sapwood, after an initial volume increase just above the water surface, water volumes increase steadily and quickly, from bottom to top. Water has reached the top of the sample by the 30-min time step. By $135 \mathrm{~min}$, volumes are high and quite uniformly distributed over the height of the sample.

Almost no difference is seen with tangential decane uptake volume profiles for the different wood species. In all cases, decane rises more quickly than water: by the 7-min time step and thereafter, decane has reached the top of all samples and no significant vertical gradient remains, except very close to the decane surface. Only the volume level is different between the different species: somewhat in the same range for spruce and fir heartwood but slightly higher for spruce than fir sample "b" and higher for pine sapwood.

The differences seen between the spruce and fir "a" samples in tangential water uptake are also seen in the radial swelling profiles. There is almost no swelling in the spruce sample above the liquid surface, but significant swelling for the portion that was immersed in water. For fir, there is only slight swelling close to the water at $1 \mathrm{~min}$, but then gradual swelling of whole sample, until it reaches about $9 \%$ at bottom and $4 \%$ at top for the $135 \mathrm{~min}$ profile. There is also no radial swelling initially in the pine sample. Then, swelling increases, and by $135 \mathrm{~min}$, the pine sample displays a somewhat uniform swelling of approximately $6 \%$.

Swelling is only due to the water adsorbed in the cell wall and thus occurs in the hygroscopic regime only, which is up to $30 \%$ moisture content (MC) or about $1501 / \mathrm{m}^{3}$. Higher volume of liquid per volume of wood indicates that lumens are being filled with water. There is a known linear relation between MC and swelling and a known effect of swelling in inducing compressive or tensile stresses (Burgert et al. 2007). Multiplying the moisture content profiles, in the hygroscopic range, by the free swelling coefficients of the three species should provide the swelling profiles; however, it is clear that the swelling profiles are much smoother that the water volume profiles, as swelling is not free and internal stresses arise. Zones that swell more will undergo compressive stresses and a reduced free swelling, while zones that swell less will undergo tensile stresses and an increased swelling resulting in the observed smooth curves, even in the pure hygroscopic region seen above $4 \mathrm{~mm}$ in spruce and fir. This explains that, in radial uptake, earlywood and latewood undergo similar swelling due to this internal interaction although the liquid volume profiles show peaks for earlywood.

\section{Conclusion}

In order to examine the influence of water sorption and swelling on liquid transport in wood, neutron imaging was used to document the time-dependent and spatial distribution of two liquids, one polar, i.e., water and one nonpolar, i.e., decane, during liquid uptake in the three orthotropic directions - longitudinal, radial and tangential—of wood samples of three species, namely spruce and fir heartwood and pine sapwood.

In terms of total volume of liquid uptaken, decane uptake displays a very linear behavior passed the first few minutes of the test, which indicates that the nonlinearity of the water uptake may be dependent on water sorption by the cell walls. Water sorption by the cell walls slows down the liquid uptake process. Both heartwoods mostly display similar liquid uptake, faster in the longitudinal and tangential orientations, and slower in the radial direction. Uptake for both water and decane is faster for pine sapwood, for all orientations. This is expected since sapwood has not undergone the transformation into heartwood, which reduces 
permeability. The difference between water and decane uptake in terms of volume of liquid is more pronounced for spruce and fir than for pine sapwood.

The spatial distribution of liquid within the samples is clearly related to the location of earlywood and latewood layers, as well as to the available paths. Although bordered and crossfield pits offer some resistance to the passage of water, the very low contact angle and high wettability of decane compared to water result in faster decane transport. This may explain, at least partly, why decane uptake is more similar for the three orthotropic orientations. The swelling profiles show that swelling is proportional to water volumes and that it is larger in those areas where water accumulation is seen.

Acknowledgments The experiments were carried out at the NEUTRA beamline of the Paul Scherrer Institute, Villigen, Switzerland. We would like to acknowledge the contributions and support of the EMPA technicians Stephan Carl, Roger Vonbank and Daniel Heer, the Paul Scherrer Institute NEUTRA support of Jan Hovind, Laurent Galerne, trainee master student from University of Rennes for helping to perform experiments both at NEUTRA and EMPA and Dr. Iwan Jerjen from EMPA for controlling of the samples before experiments with X-ray tomography.

\section{References}

Almeida, G., Leclerc, S., Perré, P.: NMR imaging of fluid pathways during drainage of softwood in a pressure membrane chamber. Int. J. Multiph. Flow 34, 312-321 (2008)

Bailey, P.J., Preston, R.D.: Some aspects of softwood permeability. Holzforschung 24, $37-45$ (1970)

Burgert, I., Eder, M., Gierlinger, N., Fratzl, P.: Tensile and compressive stresses in tracheids are induced by swelling based on geometrical constraints of the wood cell. Planta 226, 981-987 (2007)

David, R.L.: CRC Handbook of Chemistry and Physics, Internet Version 2009, 89th edn. CRC Press/Taylor and Francis, Boca Raton (2009)

Dorris, G.M., Gray, D.G.: Adsorption, spreading pressure and London force interactions of hadrocarbons on cellulose and wood fiber surfaces. J. Colloid Interface Sci. 71, 93-106 (1979)

Gardner, W.R., Mayhugh, M.S.: Solutions and tests of the diffusion equation for the movement of water in soil. Soil Sci. Soc. Am. J. 22, 197 (1958)

Hassanein, R.: Correction methods for the quantitative evaluation of thermal neutron tomography. Dissertation, ETH Zurich (2006)

Hassanein, R., Lehmann, E., Vontobel, P.: Methods of scattering corrections for quantitative neutron radiography. Nucl. Instrum. Methods A 542, 353-360 (2005)

Kitin, P., Fujii, T., Abe, H., Takata, K.: Anatomical features that facilitate radial flow across growth rings and from xylem to cambium in Cryptomeria japonica. Ann. Bot. 103, 1145-1157 (2009)

Koran, Z.: Tangential pitting in black spruce tracheids. Wood Sci. Technol. 11, 115-123 (1977)

Kulasinski, K., Guyer, R., Derome, D., Carmeliet, J.: Water adsorption in wood Microfibril-Hemicellulose system: role of the crystalline-amorphous interface. Biomacromolecules 15, 2972-2978 (2015)

Liese, W., Bauch, J.: On anatomical causes of the refractory behaviour of spruce and Douglas fir. J. Wood Sci. 19, 3-14 (1967)

National Institute of Standards and Technology. http://webbook.nist.gov/chemistry/

Otsu, N.: A threshold selection method from gray-level histograms. IEEE Trans. Syst. Man Cybern. 9(1), 62-66 (1979). doi:10.1109/TSMC.1979.4310076

O'Leary, P.O., Hodges, P.A.: The relationship between full penetration uptake and swelling of different fluids. Wood Sci. Technol. 35, 217-227 (2001)

Philip, J.R.: The theory of infiltration: 4. Sorptivity and algebraic infiltration equations. Soil Sci. 84, 257-264 (1957)

Sedighi Gilani, M., Griffa, M., Mannes, D., Lehmann, E., Carmeliet, J., Derome, D.: Visualization and quantification of liquid water transport in softwood by means of neutron radiography. Int. J. Heat Mass Transf. 55, 6211-6221 (2012)

Sedighi Gilani, M., Vontobel, P., Lehmann, E., Carmeliet, J., Derome, D.: Liquid uptake in Scots pine sapwood and hardwood visualized and quantified by neutron radiography. Mater. Struct. 47(6), 1083-1096 (2014)

Siau, J.F.: Transport Processes in Wood. Springer, NewYork (1984)

Stamm, A.J.: Density of wood substance, adsorption by wood, and permeability of wood. J. Phys. Chem. 33, 398-414 (1929) 
Thévenaz, P., Ruttimann, U.E., Unser, M.: A pyramid approach to subpixel registration based on intensity. IEEE Trans. Image Process. 7(1), 27-41 (1998)

Yaws, C.L.: Chemical Properties Handbook, pp. 159-179. McGraw-Hill, New York. ISBN 0-07-073401-1 (1999)

Zillig, W.: Moisture transport in wood using a multi-scale approach. Dissertation, Catholic University of Leuven (2009) 